\title{
Surgically Induced Astigmatism after Phacoemulsification with and without Correction for Posture-Related Ocular Cyclotorsion
}

\author{
I. Dooley \\ Waterford Regional Hospital \\ S. Charalampidou \\ Waterford Regional Hospital
}

A. Malik

Waterford Regional Hospital

See next page for additional authors

Follow this and additional works at: https://arrow.tudublin.ie/otpomart

Part of the Optometry Commons

\section{Recommended Citation}

Dooley, I., Charalampidou, S., Malik, A., Ormonde, G., Loughman, J., Molloy, L., Beatty, S.: Surgically Induced Astigmatism After Phacoemulsification With and Without Correction for Posture-Related Ocular Cyclotorsion. Journal of Cataract and Refractive Surgery, Volume 36, Issue 3, pp. 413-417. 2010. doi:10.1016/j.jcrs.2009.10.033.

This Article is brought to you for free and open access by ARROW@TU Dublin. It has been accepted for inclusion in Articles by an authorized administrator of ARROW@TU

Dublin. For more information, please contact arrow.admin@tudublin.ie, aisling.coyne@tudublin.ie, gerard.connolly@tudublin.ie.

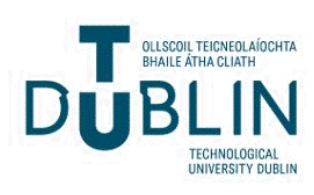


Authors

I. Dooley, S. Charalampidou, A. Malik, G. Ormonde, James Loughman, Laura Molloy, and Stephen Beatty

This article is available at ARROW@TU Dublin: https://arrow.tudublin.ie/otpomart/6 


\section{Surgically induced astigmatism after phacoemulsification with and without correction for posture-related ocular cyclotorsion}

\section{Randomized controlled study}

Ian Dooley, MRCOphth, Sofia Charalampidou, MRCOphth, Arhsed Malik, MRCOphth, Greta Ormonde, MB, James Loughman, PhD, Laura Molloy, Stephen Beatty, FRCOphth

PURPOSE: To report the impact of posture-related ocular cyclotorsion on 1 surgeon's surgically induced astigmatism (SIA) results and the variance in SIA.

SETTING: Institute of Eye Surgery, Whitfield Clinic, Waterford, Ireland.

METHODS: This prospective randomized controlled study included eyes that had phacoemulsification with intraocular lens implantation. Eyes were randomly assigned to have (intervention group) or not to have (control group) correction for posture-related ocular cyclotorsion. In the intervention group, the clear corneal incision was placed precisely at the 120-degree meridian with instruments designed to correction posture-related ocular cyclotorsion. In the control group, the surgeon endeavored to place the incision at the 120-degree meridian, but without markings.

RESULTS: The intervention group comprised 41 eyes and the control group, 61 eyes. The mean absolute SIA was 0.74 diopters (D) in the intervention group and $0.78 \mathrm{D}$ in the control group; the difference between groups was not statistically significant $(P>.5$, unpaired 2-tailed Student $t$ test). The variance in SIA was $0.29 D^{2}$ and $0.31 D^{2}$, respectively; the difference between groups was not statistically significant $(P>.5$, unpaired $\mathrm{F}$ test).

CONCLUSIONS: Attempts to correct for posture-related ocular cyclotorsion did not influence SIA or its variance in a single-surgeon series. These results should be interpreted with full appreciation of the limitations of currently available techniques to correct for posture-related ocular cyclotorsion in the clinical setting.

Financial Disclosure: No author has a financial or proprietary interest in any material or method mentioned.

J Cataract Refract Surg 2010; $\mathbf{\square}$ - @ (c) 2010 ASCRS and ESCRS

Toric intraocular lenses (IOLs) are spherocylindrical and correct for corneal astigmatism after cataract surgery. The orientation of the toric IOL in the capsular bag is critical because misalignment negates the desired effect of correcting astigmatism. If, for example, a toric IOL rotates 30 degrees off the prescribed axis of alignment, there is virtually no correction of astigmatism; if it rotates more than 45 degrees from the prescribed axis, the IOL augments the preoperative ocular cylinder. ${ }^{1}$ To select the appropriate toric IOL for implantation, the conscientious cataract surgeon must evaluate his or her individual surgically induced astigmatism (SIA) data, calculated by comparing preoperative and postoperative keratometry readings using vector analysis. ${ }^{2}$

Factors affecting SIA include the size, ${ }^{3}$ site, ${ }^{4}$ and configuration $^{5}$ of the incision; preexisting astigmatism $^{6}$; and laterality of the eye. ${ }^{5}$ Thus, surgeons should know precisely the meridian of their incision site when calculating SIA. Indeed, any error in SIA calculation will affect all subsequent calculations with respect to the power and orientation of the toric IOL to be implanted. Given that IOL selection is the most disputed factor involved in litigation related to cataract surgery, ${ }^{7}$ this potential source of error should be minimized. 
Postural changes, such as moving from an upright to a supine position, can induce a mean ocular cyclotorsional effect of 0.4 to 4.2 degrees (range 0 to 16 degrees), ${ }^{8-12}$ and this effect can be cyclotorsional or excylcotorsional. ${ }^{8}$ However, keratometry is typically recorded with the patient upright, whereas ocular surgery is performed with the patient supine. As a consequence, it has been recommended that preoperative corneal markings of the 0 - to 180 degree-meridian using specifically designed instruments should be made with the patient upright and that the markings should then be aligned with the 0 - to 80 -degree meridian of a fixation ring with the patient supine, from which the meridian of the toric IOL to be implanted is marked with a meridian marker. Furthermore, variability in the site of the surgical incision is likely to be influenced by other, as yet unidentified, causes including idiosyncratic ocular factors, corneal size, and the type of speculum used. Therefore, and for the above reasons, it would appear that SIA should be calculated in a setting in which these sources of variability are controlled as much as possible. This is especially true as we enter the era of toric IOLs.

To date, studies describing the calculation of SIA typically failed to take the precise wound meridian into account in their analysis. Two studies by AltanYaycioglu et al. ${ }^{4,5}$ did report marking the cornea preoperatively with the patient upright. However, the studies were retrospective and did not specify how the cornea was marked; therefore, no meaningful conclusions can be made about the contribution of preoperative corneal markings to SIA calculation.

Variance is the square of the standard deviation (SD) and gives an idea of the difference between the sample and the mean. A set of data distributed near the mean will have a small variance, whereas a more widely

Submitted: May 26, 2009.

Final revision submitted: July 29, 2009.

Accepted: October 8, 2009.

From the Department of Ophthalmology (Dooley, Charalampidou, Malik, Beatty), Waterford Regional Hospital, the Institute of Eye Surgery (Dooley, Charalampidou, Malik, Ormonde, Molloy, Beatty), Whitfield Clinic, and the Waterford Institute of Technology (Beatty), Waterford; Department of Optometry (Loughman), School of Physics, Dublin Institute of Technology, Dublin, Ireland.

Presented at the annual conference of the Irish College of Ophthalmologists, Kilkenny, Ireland, May 2009, and the XXVII Congress of the European Society of Cataract \& Refractive Surgeons, Barcelona, Spain, September 2009.

Corresponding author: Ian Dooley, MRCOphth, Institute of Eye Surgery, Suite 14, Whitfield Clinic, Cork Road, Waterford, Ireland. E-mail: iandooley@eustace.net. dispersed set of data may have the same mean but a significantly larger variance.

We performed a study designed to calculate the impact of attempts to correct for posture-related ocular cyclotorsion on SIA and the variance in SIA in a single-surgeon setting.

\section{PATIENTS AND METHODS}

This prospective randomized controlled study comprised consecutive patients scheduled for phacoemulsification with IOL implantation. The South East Regional Ethics Committee approved the study, which adhered to the tenets of the Declaration of Helsinki. All patients were given a written information leaflet regarding the nature of the study, and all provided written informed consent before recruitment.

Exclusion criteria were previous surgery or trauma, intraocular or otherwise, in the eye scheduled for surgery; anterior segment pathology other than cataract; intraoperative complications, including minor ones (eg, discontinuous capsulorhexis, placement of a corneal suture); and a history of connective tissue disorders or immunosuppressive therapy. An additional exclusion criterion in analyses in which postoperative visual performance was an outcome measure was noncataractous visually consequential ocular pathology (ie, age-related macular degeneration, diabetic macular edema, advanced glaucoma, vitreomacular traction syndrome, amblyopia).

\section{Randomization}

Patients were randomly assigned to 1 of 2 groups. In the intervention group, the precise meridian of the clear corneal incision (CCI) was calculated to correct for posture-related ocular cyclotorsion. In the control group, the surgeon did not make corneal markings for ensuring the CCI was precisely at the 120-degree meridian to correct for posture-related ocular cyclotorsion.

\section{Preoperative Evaluation}

All patients had a comprehensive preoperative ophthalmic examination that included uncorrected (UDVA) and corrected (CDVA) distance visual acuities; contrast sensitivity (computerized Pelli-Robson chart); manifest refraction by autorefraction (AR-360A, Nidek); keratometry, anterior chamber depth (ACD) measurement, and corneal topography by Scheimpflug imaging (Pentacam, Oculus Optikgeräte $\mathrm{GmbH}$ ); and axial length measurement by partial coherence interferometry (IOLMaster version 5, Carl Zeiss Meditec). Astigmatism was assessed preoperatively and postoperatively based on the keratometry readings of the central $6.0 \mathrm{~mm}$ cornea on corneal topography using the Scheimpflug imaging device.

\section{Surgical Technique}

All phacoemulsification procedures were performed by a right-handed surgeon (S.B.) between October 2008 and March 2009 using topical anesthesia (proxymetacaine hydrochloride $0.5 \%$ ). In the intervention group (posture-related ocular cyclotorsion corrected), the cornea was marked preoperatively at the 0 - to 180 -degree meridian using a Blakewell BubbleLevel preoperative marker (Mastel, Inc.) with the patient seated upright. Then, under the operating 
microscope, the 0- to 180-degree meridian of a Gimbel Mendez fixation ring (Mastel, Inc.) was aligned; this meridian was marked with the preoperative marker, and the site of the intended wound site was marked using a Bores meridian (axis) marker (Mastel, Inc.). The 120-degree meridian was chosen because this site seemed natural to the operating surgeon when he performed the first case in the intervention group; this meridian was used in all subsequent cases in that group. A corneal incision site (centered at 120 degrees) was created using a $2.75 \mathrm{~mm}$ full-angled knife (Alcon, Inc.). A $1.0 \mathrm{~mm}$ paracentesis was created 3 clock hours to the left of the CCI (not specifically measured); this was the paracentesis site regardless of whether surgery was in a right eye or the left eye. In the control group, the surgeon endeavored to make the CCI and paracentesis at the same sites (120 degrees and 3 clock hours, respectively, to the left of the CCI) but without the aid of the instrumentation described above.

The same surgical technique was then used in both groups. After a 2-step CCI (2.00 $\mathrm{mm}$ long, $2.75 \mathrm{~mm}$ wide) was created in the perilimbal region at the 120-degree meridian using the markings in the intervention group and the surgeon's estimate in the control group, a $1.0 \mathrm{~mm}$ paracentesis was created 3 clock hours to the left of the CCI. Then, sodium hyaluronate $1 \%$ (Healon) was injected into the anterior chamber and a $6.0 \mathrm{~mm}$ continuous curvilinear capsulorhexis was created. After hydrodissection, phacoemulsification of the nucleus was performed using an Infiniti phaco unit (Alcon, Inc.) and the soft lens matter was aspirated. Next, sodium hyaluronate $1 \%$ was injected to inflate the capsular bag and anterior chamber. Then, an IOL (Tecnis ZA9003, Abbott Medical Optics, Inc.) was implanted in the capsular bag using an unfolder and cartridge (AMO EmeraldT Series, Abbott Medical Optics, Inc.). And remaining ophthalmic viscosurgical device in the anterior chamber and posterior chamber was evacuated using the phaco unit's irrigation/ aspiration system. Stromal hydration was performed to achieve wound integrity, and intracameral cefuroxime $1 \mathrm{mg}$ in $0.1 \mathrm{~mL}$ of sterile water for injection was administered via the paracentesis. A single drop of apraclonidine $1 \%$ and an aliquot of fucidic acid ointment $1 \%$ were administered to the corneal surface and a cartella shield (BD Visitec Universal Eye Shield, Becton, Dickinson \& Co.) was placed over the eye.

\section{Postoperative Evaluation}

All eyes were examined 2 weeks and 6 weeks postoperatively. Outcome measures were recorded at the 6-week postoperative visit and included UDVA, CDVA, contrast sensitivity, manifest refraction by autorefraction, keratometry, ACD, and corneal topography measured using the same devices as preoperatively.

\section{Statistical Analysis}

Surgically induced astigmatism was calculated using the arithmetic and vector analysis methods. The SIA in both groups was calculated and compared (unpaired 2-tailed Student $t$ test), as was the variance in SIA (unpaired F-test, variance ratio test). A $P$ value less than 0.05 was considered statistically significant.

Refraction is usually written as sphere, cylinder, and axis. This conventional format may characterize a single refraction but is not suited to statistical analysis. There are no problems with analysis of the spherical component; the difficulties reside with the astigmatism. Astigmatism is characterized by a magnitude expressed in diopters (D) and a direction reported in degrees. For statistical analysis, these incommensurable entities must be converted to vectors or similar entities (such as polar values ${ }^{13}$ ).

In arithmetic analysis, the magnitudes of cylinders are added together to calculate a mean. Even if the absolute value is taken, the direction component of the resultant cylinder cannot be derived by this method. Therefore, arithmetic analysis, while convenient, is wholly inaccurate used.

Vector analysis treats cylinder as a vector with magnitude and direction. The refractive error is expressed in sphere/ cylinder $\times$ axis format. Two or more vectors can be compared with these techniques. In this study, SIA was determined using a free online SIA calculator that uses the Holladay method of vector analysis (http://doctor-hill. com/physicians/download.htm. Accessed December 4, 2009). ${ }^{14,15}$

\section{RESULTS}

This study evaluated 102 eyes (54 left, 48 right) of 86 patients. The mean age of the 34 men $(40 \%)$ and 52 women $(60 \%)$ was 70.5 years $\pm 10.2(\mathrm{SD})$.

In all eyes, the mean UDVA was $0.72 \pm 0.65 \log$ MAR preoperatively and $0.15 \pm 0.30 \log$ MAR postoperatively and the mean CDVA, $0.38 \pm 0.48 \operatorname{logMAR}$ and $0.04 \pm 0.28 \log$ MAR, respectively; the UDVA and CDVA were statistically significantly better postoperatively than preoperatively $(P<.001$, paired 2 -tailed Student $t$ test). The mean log of contrast sensitivity improved significantly from $1.15 \pm 0.43 \log$ units preoperatively to $1.59 \pm 0.10 \log$ units postoperatively $(P<.001$, paired 2-tailed Student $t$ test $)$.

The mean absolute preoperative astigmatism was $1.04 \pm 0.59 \mathrm{D}$ in the intervention group and $1.08 \pm$ $0.71 \mathrm{D}$ in control group; the difference between the groups was not statistically significant $(P>.5$, unpaired 2-tailed Student $t$ test). The mean absolute spherical equivalent (SE) was statistically significantly lower postoperatively $(0.59 \pm 0.48 \mathrm{D})$ than preoperatively $(2.72 \pm 3.15 \mathrm{D})(P<.001$, paired 2-tailed Student $t$ test), with a mean prediction error of $0.51 \pm 0.45 \mathrm{D}$ (range -1.95 to $+1.16 \mathrm{D}$ ). There was no significant difference in the mean change in absolute SE between the intervention group $(2.45 \pm 2.15 \mathrm{D})$ and the control group $(2.37 \pm 2.71 \mathrm{D})(P>.5$, unpaired 2-tailed Student $t$ test).

Using the arithmetic method of analysis, the mean absolute SIA was $0.51 \pm 0.53 \mathrm{D}$ in the intervention group and $0.48 \pm 0.39 \mathrm{D}$ in the control group; the difference between groups was not statistically significant $(P>.5$, unpaired 2-tailed Student $t$ test). However, the variance in SIA was significantly greater in intervention group $\left(0.28 \mathrm{D}^{2}\right)$ than in the control group $\left(0.16 \mathrm{D}^{2}\right)(P=.037$, unpaired F-test $)$.

Using vector analysis, the mean SIA was $0.72 \pm$ $0.54 \mathrm{D}$ with a variance of $0.32 \mathrm{D}^{2}$ in the intervention group and $0.70 \pm 0.56 \mathrm{D}$ with a variance of $0.17 \mathrm{D}^{2}$ 
Table 1. Mean SIA by group.

\begin{tabular}{lccccc}
\hline & \multicolumn{2}{c}{ Right Eyes } & & \multicolumn{2}{c}{ Left Eyes } \\
\cline { 2 - 3 } SIA & $\begin{array}{c}\text { Correction Attempt Made } \\
(\mathrm{n}=17)\end{array}$ & $\begin{array}{c}\text { No Correction Attempt Made } \\
(\mathrm{n}=32)\end{array}$ & $\begin{array}{c}\text { Correction Attempt Made } \\
(\mathrm{n}=25)\end{array}$ & $\begin{array}{c}\text { No Correction Attempt Made } \\
(\mathrm{n}=28)\end{array}$ \\
\hline Mean (D) & 0.63 & 0.70 & 0.81 & 0.87 \\
SD (D) & 0.41 & 0.53 & 0.63 & 0.55 \\
Variance $\left(\mathrm{D}^{2}\right)$ & 0.17 & 0.28 & 0.40 & 0.30 \\
\hline SIA = surgically induced astigmatism & & & \\
\hline
\end{tabular}

in the control group. Neither the mean absolute SIA nor the variance of SIA was statistically significantly different between the 2 groups (both $P>.5$; unpaired 2-tailed Student $t$ test for SIA and unpaired F-test for variance).

[Q3] Table 1 shows the mean SIA by group. There was no significant difference in the SIA or its variance between right eyes and left eyes in the intervention group or in the control group (both $P>.5$; unpaired 2-tailed Student $t$ test for SIA and unpaired F-test for variance). There was no significant difference in the mean SIA or its variance between the intervention group and the control group in right eyes (SIA: $P>.5$, unpaired 2-tailed Student $t$ test; variance: $P=.325$, unpaired F-test) or in left eyes (SIA: $P>.5$, unpaired 2-tailed Student $t$ test; variance: $P=.499$, unpaired F-test).

\section{DISCUSSION}

This study found that for the same surgeon, attempts to correct for posture-related ocular cyclotorsion did not affect SIA or its variance. The mean SIA in our cohort of 102 eyes was $0.76 \pm 0.54 \mathrm{D}$. This is comparable with results in previous phacoemulsification studies $^{3-5,16}$ in which the postoperative SIA ranged from 0.30 to $1.55 \mathrm{D}$ but in which no attempt was made to correct for posture-related ocular cyclotorsion.

In a retrospective study of surgical outcomes of 3 right-handed surgeons, Altan-Yaycioglu et al., ${ }^{5}$ found a statistically significant difference in mean SIA after uneventful cataract surgery between right eyes (1.08 $\pm 0.93 \mathrm{D})$ and left eyes $(1.36 \pm 1.00 \mathrm{D}(P<.001)$. These levels were significantly higher than in our study $(0.68$ $\pm 0.49 \mathrm{D}$ and $0.84 \pm 0.59 \mathrm{D}$, respectively). Altan-Yaycioglu et al. did not describe the preoperative corneal marking method with the patient upright. Futhermore, although the initial incision was $2.85 \mathrm{~mm}$ in their study, it was enlarged to $4.00 \mathrm{~mm}$ for IOL implantation. We used a $2.75 \mathrm{~mm}$ incision size, which is closer to that necessary for implantation of commonly used toric IOLs. We believe 1 reason for the discrepancy in the magnitude of the SIA between the 2 studies is because ours was a single-surgeon series; however, we believe the difference is mainly attributable to the significantly smaller incisions in our study.

We found a trend toward a greater mean SIA and its variance in left eyes than in right eyes, and this trend approached statistical significance $(P=.096$, unpaired 2-tailed Student $t$ test). The greater SIA in left eyes, which was statistically significant in the Altan-Yaycioglu et al. ${ }^{5}$ study, was in the eye that was contralateral to the surgeon's dominant and operating hand. In both studies, the CCI was located in the superotemporal quadrant in right eyes and the superonasal quadrant in left eyes, and this may have contributed to the influence of laterality on SIA. Nasal CCIs are associated with greater SIA than temporal CCIs because they are closer to the visual axis ${ }^{4}$; this may account for the effect of laterality on SIA in both studies.

The calculation of a given surgeon's SIA is an essential step in the preparation for toric IOL implantation. The free online toric IOL calculator we used incorporates the surgeon's SIA (magnitude), site of CCI (direction), and patient's biometry in its calculations to recommend a given power and orientation of the toric IOL to be implanted. It is somewhat reassuring that our study suggests that attempts to correct for posture-related ocular cyclotorsion do not influence the calculation of SIA or its variance.

However, our results must be interpreted with full appreciation of the limitations inherent in the method of marking the cornea preoperatively in an attempt to achieve consistent meridional location of the CCI. If, for example, the marking error (between the 2 steps involved) is imprecise by 0.4 to 4.0 degrees, the potential benefit of such markings is forfeited. In other words, a more precise technique of correcting for posture-related ocular cyclotorsion (eg, binocular 3-dimensional infrared videooculography) ${ }^{10}$ might have yielded different results.

In conclusion, and with full appreciation of the limitations inherent in the technique of marking the eye preoperatively to ensure the $\mathrm{CCI}$ is made at a given meridian, calculation of SIA (or the variance in such calculations) was not adversely affected by failing to correct for posture-related ocular cyclotorsion. 


\section{REFERENCES}

1. Novis C. Astigmatism and toric intraocular lenses. Curr Opin Ophthalmol 2000; 11:47-50

2. Naeser K. Assessment and statistics of surgically induced astigmatism. Acta Ophthalmol 2008; 86 (issue thesis 1):5-28

3. Moon SC, Mohamed T, Fine IH. Comparison of surgically induced astigmatisms after clear corneal incisions of different sizes. Korean J Ophthalmol 2007; 21:1-5. Available at: http:// www.ncbi.nlm.nih.gov/pmc/articles/PMC2629691/pdf/kjo-21-1. pdf. Accessed December 4, 2009

4. Altan-Yaycioglu R, Akova YA, Akca S, Gur S, Oktem C. Effect on astigmatism of the location of clear corneal incision in phacoemulsification of cataract. J Refract Surg 2007; 23:515-518

5. Altan-Yaycioglu R, Pelit A, Evyapan Ö, Akova YA. Astigmatism induced by oblique clear corneal incision: right vs left eyes. Can J Ophthalmol 2007; 42:557-561. Available at: http://article.pubs. nrc-cnrc.gc.ca/RPAS/rpv?hm $=$ HInit\&calyLang = eng\&journal $=$ cjo\&volume $=42 \&$ afpf $=i 07-079$.pdf. Accessed December 4 , 2009

6. Tejedor J, Murube J. Choosing the location of corneal incision based on preexisting astigmatism in phacoemulsification. Am J Ophthalmol 2005; 139:767-776

7. Brick DC. Risk management lessons from a review of 168 cataract surgery claims. Surv Ophthalmol 1999; 43:356-360

8. Swami AU, Steinert RF, Osborne WE, White AA. Rotational malposition during laser in situ keratomileusis. Am J Ophthalmol 2002; 133:561-562

9. Becker R, Krzizok T, Wassill H. Lageabhängigkeit der Augenstellung in der torsionalen Ebene bei Patienten ohne Binokularsehen. [Influence of body position on ocular cycloposition in patients without binocular vision]. Klin Monatsbl Augenheilkd 2006; 223:48-51
10. Becker R, Krzizok TH, Wassill H. Use of preoperative assessment of positionally induced cyclotorsion: a video-oculographic study. Br J Ophthalmol 2004; 88:417-421. Available at: http://www. ncbi.nlm.nih.gov/pmc/articles/PMC1772033/pdf/bjo08800417. pdf. Accessed December 4, 2009

11. Smith EM Jr, Talamo JH. Cyclotorsion in the seated and supine patient. J Cataract Refract Surg 1995; 21:402-403

12. Smith EM Jr, Talamo JH, Assil KK, Petashnick DE. Comparison of astigmatic axis in the seated and supine positions. J Refract Corneal Surg 1994; 10:615-620

13. Naeser K, Hjortdal J. Polar value analysis of refractive data. J Cataract Refract Surg 2001; 27:86-94

14. Hill W. Expected effects of surgically induced astigmatism on AcrySof toric intraocular lens results. J Cataract Refract Surg 2008; 34:364-367

15. Holladay JT, Moran JR, Kezirian GM. Analysis of aggregate surgically induced refractive change, prediction error, and intraocular astigmatism. J Cataract Refract Surg 2001; 27:61-79

16. Kohnen S, Neuber R, Kohnen T. Effect of temporal and nasal unsutured limbal tunnel incisions on induced astigmatism after phacoemulsification. J Cataract Refract Surg 2002; 28: 821-825

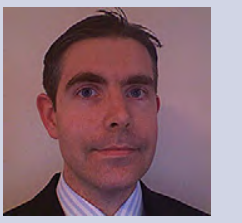

First author: Ian John Dooley, MRCOphth Department of Ophthalmology, Waterford Regional Hospital, publin, Ireland 